\title{
Current Controversies Regarding Body Checking and Tackling in Youth Sports
}

\section{Peter K. Kriz, MD}

\author{
Address \\ Division of Sports Medicine, Departments of Orthopedics and Pediatrics, Rhode \\ Island Hospital/Brown University, 593 Eddy St., Providence, RI 02903, USA \\ Email: Peter_Kriz@brown.edu
}

Published online: 3 April 2015

(C) Springer International Publishing AG 2015

\section{This article is part of the Topical Collection on General Pediatrics}

Keywords Body checking · Tackling · Concussion · Head injury · Youth sports

\section{Opinion statement}

Head and spinal injuries in collision sports such as American football, ice hockey, and lacrosse affect millions of youth and adolescent athletes in the USA. Strategies to reduce sport-related concussion and catastrophic spinal cord injuries have increased over the past few decades, with rule changes limiting body checking at younger levels of youth ice hockey and bans on spear tackling in American football. Until recently, sports medicine communities have focused their efforts on providing consensus statements and guidelines pertaining to the detection, evaluation, and management of sport-related concussion. Many of these recommendations have extrapolated data from adult studies as limited research is available on youth athletes. There is a movement among sports medicine clinicians and researchers to collaborate with youth sports organizations to provide scientific data and answers to questions pertaining to youth collision sport injury. Changes and advances in protective equipment have not resulted in a dramatic decline in collision sport head injuries. But several strategies hold promise, such as teaching proper body checking and tackling technique; establishing and enforcing rules that limit head contact and intent-to-harm hits to vulnerable players; implementing participation strategies determined by age, size, and physical maturity level; and introducing injury prevention strategies to reduce head injuries. By administering these interventions collectively, a safer environment for our youth and adolescent collision sport athletes to engage in healthy competition can be provided. In addition, evaluation of our collective intense sport culture is needed as societal pressures are also likely contributing to injuries and unintended consequences. Pediatricians play a vital role in advocating for the safety of youth collision sport athletes as medical providers, parents, coaches, and as board members and in advisory positions of youth sports organizations. 


\section{Introduction}

Over the past few decades, the debate regarding body checking and tackling in youth sports has heated up, largely due to the concussion "epidemic," but also due to several high-profile catastrophic injuries. Among those injured include (1) Zachary Lystedt (2006), who sustained second impact syndrome during a middle school football game in Washington, (2) Matt Brown (2010), and (3) Jack Jablonski (2012), who each sustained catastrophic cervical spine injuries in high school ice hockey games in Massachusetts and Minnesota, respectively. In May 2014, a summit meeting at the White House occurred regarding the topic of safety in youth contact/collision sports, with goals of raising awareness about the consequences of head injuries in youth sports and increasing research on concussion prevention [1]. Roundtable discussions such as the Aspen Institute (2012) featured concussion experts including Drs. Robert Cantu, Gerry Gioia, and Julian Bailes, as well as representatives from youth football organizations. A diplomatic discussion regarding the best approach to improving safety and reducing head injury in youth football ensued [2]. A lesser-known event took place at Mayo Clinic in 2010, led by Dr. Michael Stuart, Chief Medical Officer of USA Hockey. This conference provided action items aimed at reducing concussion and head injury in youth hockey and showcased efforts of Minnesota Hockey's Hockey Education Program [3].

Sport-related concussion (SRC) in youth sports has increasingly received attention from the scientific community. Currently, there are four different guidelines/ position statements pertaining to SRC. These include (1) the Consensus Statement on Concussion in Sport derived from the 4th International Conference on Concussion in Sport (Zurich, Switzerland, November 2012) $[4 \bullet]$, (2) Summary of Evidence-Based Guideline Update:
Evaluation and Management of Concussion in Sports (American Academy of Neurology, 2013) [5], (3) American Medical Society for Sports Medicine Position Statement: Concussion in Sport (2013) [6], and (4) Institute of Medicine's Sports-Related Concussions in Youth report (2014) [7]. All four statements/guidelines allude to the fact that evidence-based recommendations are difficult to generate due to limited research available on youth athletes.

In answering the central question, "Should body checking and tackling be taught/permitted in youth sports," the following key questions should be considered: (1) does current research and literature pertaining to body checking and tackling in youth sports provide a clear-cut answer? (2) Is there expert opinion consensus regarding body checking and tackling in youth sports? (3) How do age, size, and physical maturity factor into decisions to encourage/discourage body checking and tackling in youth sports? (4) What role do rule change/ enforcement, educational and prevention strategies, and sport culture/behavior modification have regarding permission/prohibition of body checking and tackling in youth sports?

In recent years, several proposals pertaining to the introduction of body checking and tackling in youth sports have been examined by youth sports organizations, sports medicine experts, and clinical researchers. These include using age/grade-based cutoffs, physical maturity cutoffs, limiting contact in practices/ instruction, rule changes to reduce injury, educational and injury prevention strategies to reduce concussion and head injury, and addressing sport culture through behavioral modification of players, coaches, and parents.

\section{Treatment options}

\section{Eliminate body checking and tackling under age 14}

In the past few years, research pertaining to youth collision sport participation has emerged which supports the delay of body checking and tackling until physical maturity has been achieved. In 2010, Emery and colleagues compared concussion injury risk between Pee Wee (age 12 and under) youth ice hockey players in the Canadian provinces of Alberta, in which body checking was allowed, and Quebec, in which body checking was not allowed. The authors found a greater than threefold increased risk of concussion and all game-related 
injury (including severe concussion with time loss $>10$ days and severe injury with time loss $>7$ days) in the Alberta league compared to the Quebec league [8]. Influenced by Emery's study findings, USA Hockey and Hockey Canada eliminated body checking at the 12-and-under level in 2011 and 2013, respectively. Daniel and colleagues performed an in-helmet accelerometer study in $7-$ 8-year-old youth American football players during games and practices for a single season. Linear acceleration forces ranged from 10 to $100 \mathrm{G}$, with the majority of high-level impacts $(29 / 38$ impacts $>40 \mathrm{G})$ occurring during practices. This showed youth football players were capable of generating high head accelerations that have been demonstrated to cause concussions in adult football players [ $9 \bullet$. As youth football players between 6 and 13 years old comprise $70 \%$ of the 5 million American football participants in the USA [9•], this clinical research has significant bearing on the future direction of collision sport participation among youth athletes.

Dr. Robert Cantu, one of the nation's leading experts regarding SRC, has similarly proposed the elimination of tackling in football altogether under the age of 14 [2]. While not opposed to restricting collision sport activity until age 16 or when an athlete has undergone skeletal maturity or the onset of axillary hair, Dr. Cantu has supported high school entry as an arbitrary cutoff.

Introduce body checking and tackling under age 14

In 2011, Emery and colleagues published a follow-up youth ice hockey study which analyzed data from Bantam (age 14 and under) from Alberta and Quebec. The Alberta players had 2 years of body checking experience during Pee Wee-level play, while the Quebec Bantam players had not had prior body checking experience. Alberta players had a $33 \%$ lower incidence of injuries resulting in time loss from play $>7$ days. This result was unexpected and called for closer consideration of an optimal age and method for introducing body checking to youth hockey players [10]. Dr. Kevin Guskiewicz, a leading expert and researcher in youth concussion, contends that teaching proper tackling techniques to youth collision sport athletes should occur prior to high school [11]-before physical maturity and before athletes get "bigger, stronger, and faster"-and the laws of physics change the rules of engagement in these respective collision sports.

In recent years, youth sports organizations have developed programs that integrate teaching and learning proper body checking and tackling technique into their respective curricula. Examples include USA Football's "Heads Up Football," which includes a program that teaches and reinforces proper tackling mechanics with a focus on reducing helmet contacts [12]. Similarly, USA Hockey has developed an introduction to body contact as part of its coaching education program. This initiative focuses on teaching body contact to 8-andunder and 10-and-under players, with a gradual phase-in during 12-and-under play prior to permitting body checking at the 14-and-under and older levels [13].

\section{Base collision sport participation on physical maturity rather than age-based cutoffs}

Age/grade-based cutoffs alone may not be sufficient. Most youth sports organizations group youth athletes by chronological or relative age, resulting in youth athletes typically falling within 12-24 months of their fellow participants' 
birthdates (Table 1). The difficulty with age/grade-based cutoffs lies with the significant variability regarding when an adolescent enters later stages of puberty. Adolescent athletes often fall into one of two categories: early maturers or late bloomers. Unlike youth sports, high school sport participation allows a wider age spread and therefore younger, less physically mature adolescents to oppose older, physically mature adolescents. Age, weight, and height discrepancies can be 4 years, $100 \mathrm{lb}$, and one foot, respectively. In smaller-size high schools throughout the USA, freshman football players play varsity football and frequently play both offense and defense-a necessity for a smaller school to field a team with enough players. High school ice hockey, unlike other high concussion rate contact/collision sports such as football, lacrosse, and soccer, lacks stratification by age grouping, largely in part due to prohibitive costs associated with equipment, transportation, and ice time. Fielding a varsity, junior varsity, and freshman ice hockey team is cost-prohibitive for most public and private schools, resulting in the majority of public high schools fielding varsity ice hockey teams only. Consequently, it is not uncommon at the varsity level for younger, less physically mature players to oppose older, post-pubertal players who have achieved increased strength, power, and speed as a result of completing pubertal development. For instance, a scenario involving a 14-yearold 140-lb freshman forward battling for possession of the puck with an 18year-old 200-lb senior defenseman can be commonplace.

Clinical research involving youth collision sport athletes is beginning to assess the risks of younger, physically immature athletes playing varsity collision sports as high school sports allow younger, more skilled players to "play up." Work performed by Rhode Island Hospital, Boston Children's Hospital, and South Shore Hospital (MA) sports medicine researchers on high school-age collision sport athletes shows that physically immature males, as rated by a selfassessment pubertal developmental scale, have longer recoveries from concussions compared to physically mature males (personal communication, unpublished data). These preliminary findings suggest that utilizing arbitrary chronologic age cutoffs should be approached with caution until future research can help determine optimal entry points into collision sports based on the many variables influencing injury risk.

\section{Allow body checking/tackling, but limit contact in practice}

Several youth sports organizations have begun restricting contact in practice and instructional drills as a consequence of Daniel's youth football accelerometer study results [9•] and the initiatives of several collegiate football conferences (e.g., Ivy League, PAC-12). As of 2012, Pop Warner Football has reduced contact to $1 / 3$ of practice hours, and eliminated intentional head-to-head contact in practice. In 2014, the National Federation of State High School Associations (NFHS) recommended reduced contact in high school-sanctioned football practices during both the regular and off-season. It is important to note that no data yet exist to support limited contact in practice as an effective intervention in reducing concussive injury in collision sports.

In 2012, Jack Jablonski sustained a catastrophic spinal cord injury as a result of a check-from-behind (CFB) hit in a Minnesota high school hockey game. At the 


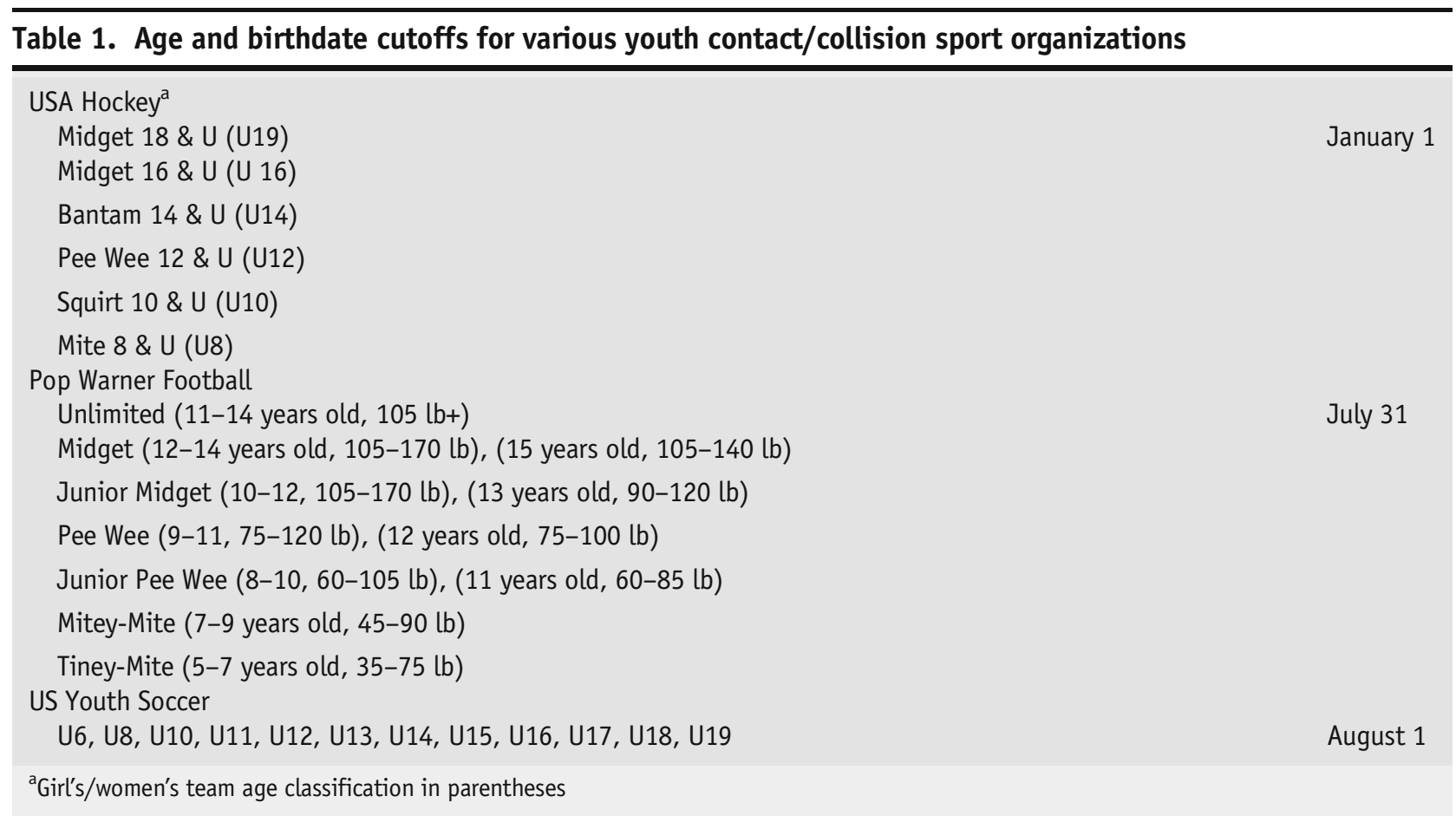

time of the injury, CFB resulted in a 2-min minor penalty. 2 weeks after Jablonski's injury, the Minnesota State High School League implemented a 5min major penalty for CFB infractions [14•]. In 2014, this rule change was adopted nationally in high school ice hockey by the NFHS.

Tom Smith, a former junior hockey player from Massachusetts, sustained two spinal cord injuries in 2008 and 2009. He has developed a Look-Up Line $^{\mathrm{TM}}$-ice hockey's version of a warning track in baseball-to act as a visual cue to players that they are entering a "danger zone," where reckless play along the dasher boards could potentially result in catastrophic injury. The 40-in. bright orange band is painted on the ice around the perimeter of the rink. As of November 2014, 250 rinks in 25 states have implemented the band. USA Hockey has appointed a Safety Task Force to study the Look-Up Line ${ }^{\mathrm{TM}}$ and other safety enhancements prior to considering any mandates. Currently, installation of a Look-Up Line ${ }^{\mathrm{TM}}$ in hockey rinks is strictly voluntary. Though these strategies hold promise, there are no data currently demonstrating their effectiveness at reducing injury.

\section{Educational and injury prevention efforts}

Youth collision sports organizations, in conjunction with medical organizations such as the Center for Disease Control and Prevention, have stepped up their educational campaigns in recent years, developing multimedia educational messages and online training programs for coaches, players, and parents [15]. While the effort to improve concussion education has been praiseworthy, critics of these educational efforts have raised concerns that educational campaigns are largely ineffective if knowledge transfer and action stages do not occur. Kroshus 
and colleagues surveyed 146 players on six Division I male ice hockey teams before and after the players had received NCAA-mandated concussion educational interventions. Five teams had received education in a handout/e-mail format, while one team viewed an educational video. The authors found that no significant improvements in concussion knowledge occurred among players, and only a very small decrease in intention to continue playing with concussion symptoms occurred [16•]. This study illustrates the tendency of collision sport players to minimize concussion as an injury and emphasizes the critical need for knowledge transfer and action among players and coaches.

Neck strengthening exercises-historically an integral part of strength and conditioning among American football players and wrestlers-has recently received renewed attention as a prevention strategy for SRC among contact/ collision sport athletes. Collins and colleagues recently assessed neck strength and neck circumference measurements in over 6,700 high school athletes over a 2 -year period. Concussed athletes had (1) smaller neck circumferences compared to athletes who did not report concussion over the study period, (2) smaller neck circumferences and larger head circumferences compared to nonconcussed athletes, and (3) less neck strength compared to non-concussed athletes. The authors determined that for every pound increase in neck strength, odds of concussion fell by $5 \%$ (OR=0.95, $95 \%$ CI 0.92-0.98) [17•].

In addition to neck strengthening, anticipation of collision has been proposed to be a prevention strategy in reducing risk of SRC. Eckner and colleagues performed a biomechanical study in 46 male and female contact sport athletes aged 8-30 years. Maximum isometric neck strength was measured in various anatomic planes, and a loading apparatus then applied impulsive forces to the athletes' heads during both baseline and anticipatory cervical muscle activation conditions. The authors determined that greater isometric neck strength and anticipatory activation were independently associated with decreased head peak linear velocity and peak angular velocity after impulsive loading across all planes of motion $(p<0.001)$, concluding that neck strength and impact anticipation are potentially modifiable risk factors for SRC, and suggesting that interventions aimed at increasing neck strength and reducing unanticipated impacts may reduce SRC incidence among contact/collision sport athletes [18].

Many youth sports organization officials, medical personnel, coaches, parents, and players have argued that rule changes and enforcement that focuses on eliminating intent-to-harm, head contact, and "targeting" behavior are more pressing issues than assigning an age cutoff for introducing body checking and tackling in youth sports. Behavioral modification in collision sports has been a concept gaining popularity in an effort to reduce SRC, particularly in ice hockey. Fair Play is a behavior modification program that utilizes team penalties to promote sportsmanship by positively reinforcing assertive play (e.g., controlled play, no intent-to-injure behavior) and negatively reinforcing aggressive play (intent-to-injure or intimidate, hits to the head, checking from behind). Initiated in Nova Scotia and Quebec, Fair Play has been utilized by Minnesota Hockey since 2004. Fair Play points are rewarded to (or withheld from) teams that take less than (or exceed) a given number of penalty minutes allotted in a game. Team standings and tournament results are determined not only by wins 
and losses, but also by team Fair Play points [14•]. Roberts and colleagues have published results evaluating the effectiveness of Fair Play rules reducing injury in ice hockey. During a 1994 Junior Hockey (<20-year-old) tournament in Minnesota, Fair Play (FP) rules were utilized for 24 round-robin games, while "regular" rules (RR) were used for the tournament's championship round (seven games). The FP/RR injury ratio was 1:4.8, the average number of penalties per game was 7.1 in FP compared to 13 in RR, and the number of rough play/injury penalties was four times higher in RR games [19]. As of 2013, 150 of 600 (25\%) of Minnesota Invitational Tournaments utilize Fair Play rules [14•].

While Fair Play has received national recognition and attention [20], implementation of this behavioral modification outside of Minnesota has been challenging to achieve, as sport culture and tradition tend to resist fundamental rule changes. However, through educational and injury prevention efforts by sports medicine clinicians, researchers, and athletes whom have had their playing careers shortened by recurrent concussions, leadership of youth hockey organizations is giving careful consideration to Fair Play implementation. Vermont State Amateur Hockey Association will use Fair Play for its state tournament for the 2014-15 season [21].

\section{Sport cultural change among coaches, officials, parents, and educational institutions}

While there has been some progress regarding behavioral modification in collision sports, other facets of sport culture lag behind considerably, and there have been a number of disturbing trends. In September 2012, a lopsided Pee Wee football game in Central Massachusetts resulted in five players from the team on the losing end of a 52-0 blowout sustaining concussions. Neither the coaches nor the officials intervened to end the game, and the fifth head injury occurred on the final play of the game. The referees were barred from officiating any more contests in the Central Massachusetts Pop Warner league, the opposing coaches were suspended for the rest of the season by league officials, and the presidents of both programs were subsequently placed on probation [22]. In January 2002, a 44-year-old father in a Boston suburb was convicted of involuntary manslaughter for beating to death another parent in a rink following an injury to his son during a pickup hockey game [23].

Compared to a generation ago, youth athletes today have exponentially more athletic exposures each week, as it has become routine to play on multiple teams and to play multiple (contact/collision) sports each season. Most youth sports have become three-season or year-round commitments. Lazy summer months of bike riding and swimming have been replaced by tournaments, elite camps, and showcases in the quest for college athletic scholarships. While such a trend has contributed to the epidemic of overuse injuries in youth and adolescent athletes, this is also a likely factor in recurrent concussions in youth athletes, as windows of opportunity for brain recovery from SRC have become narrower.

Educational institutions are also responsible for contributing to disturbing cultural trends in a sport. In recent years, several Division I universities have offered college scholarships to eighth-grade football players [24]. In the sport of lacrosse, it has become commonplace for Division I universities to have high school freshmen and sophomores verbally commit to play at their institutions $[25,26]$. Why is this concerning? Early commitment creates a culture of 
increased athletic exposures at a younger age group (e.g., middle school), transferring a higher volume and intensity of participation to a less physically mature population. This results in more athletes and their families risking recurrent, cumulative injuries including SRC, hoping for a payoff in the form of a collegiate athletic scholarship. Consequently, pediatric sports medicine physicians are treating more 13- and 14-year-old athletes with multiple concussions whom are in jeopardy of being retired from a sport even before their high school careers, let alone a collegiate or professional career.

Lastly, as skill level and competition for Division I ice hockey scholarships and roster spots has increased, so has a trend for high school and post-graduate players to hone their skills in elite junior programs in the USA in an effort to matriculate and continue their hockey careers at a US university or college. Just like professional ice hockey leagues, these junior leagues permit fighting, a known risk factor for SRC-related complications including cognitive impairment.

\section{Conclusion}

Should body checking and tackling be taught/permitted in youth sports? There is not a clear-cut answer, but we are headed in the right direction. Currently, there is a research and expert opinion that supports both elimination as well as introduction of body contact in youth collision sports. The precise timing of proper body checking and tackling technique introduction at younger levels in order to reduce concussive injury in older players has yet to be determined. Age, size, and level of physical maturity are all important factors for parents and pediatricians to consider when assessing a youth athlete's readiness to participate in collision sports.

Sports medicine clinicians, researchers, and youth sports organizations alike have recently shifted efforts away from generating consensus statements and guidelines. Instead, efforts are being directed toward gathering youth sportsspecific data, rather than extrapolating data from collegiate and professional athletes, to measure the effect of interventions to reduce injury. Rule changes, entry cutoffs based on anthropometrics and physical maturity, educational efforts, injury prevention tactics, behavioral modifications, and "common sense" recommendations have been proposed and implemented to varying degrees across the youth sports landscape. Currently, consensus opinion among sports medicine experts and researchers remains that rule changes/enforcement, and knowledge transfer and action from educational interventions are more likely to reduce head and spinal injuries from collision sport participation than changes in protective equipment. Opportunities exist for pediatricians to assist youth sports organizations with knowledge transfer and action stages among their members, whether they become involved as parents, coaches, board members, or advisors in an organization or as lobbyists for legislative action in their respective states. While culture and tradition in a sport run deep, momentum to provide our collision sport youth athletes a safer environment to remain active and healthy is building. Parents, coaches, officials, youth sports organizations, educational institutions, and collegiate athletic associations share the responsibility to improve the culture in youth sports. Finally, research necessary to determine the efficacy of safety and injury prevention interventions 
and the community support to change culture and implement these interventions are beginning to receive appropriate attention.

\section{Compliance with Ethics Guidelines}

\section{Conflict of Interest}

Peter K. Kriz declares that he has no conflict of interest.

\section{Human and Animal Rights and Informed Consent}

This article does not contain any studies with human or animal subjects performed by any of the authors.

\section{References and Recommended Reading}

Papers of particular interest, published recently, have been highlighted as:

- Of importance

1. Eilperin J. First-ever summit on sports concussions held at the White House. http://www.washingtonpost.com/ politics/first-ever-summit-on-sports-concussions-heldat-the-white-house/2014/05/29/bec19bec-e74d-11e3a86b-362fd5443d19_story.html. Accessed 23 November, 2014.

2. Aspen Institute. Playing safety: the future of youth football? Roundtable discussion. November 9, 2012. http://www.aspeninstitute.org/sites/default/files/ content/docs/sports/playing_safety_110912 transcript.pdf. Accessed 23 November, 2014.

3. Smith AM, Stuart MJ, Greenwald RM, Benson BW, Dodick DW, Emery C, et al. Proceedings from the ice hockey summit on concussion: a call to action. Curr Sports Med Rep. 2011;10(4):241-7.

4. McCrory P, Meeuwisse WH, Aubry M, Cantu B, Dvorak J, Echemendia RJ, et al. Consensus statement on concussion in sport: the 4th International Conference on Concussion in Sport held in Zurich, November 2012. Br J Sports Med. 2013;47(5):250-8.

This article is a revision and update of recommendations developed following the 1st (Vienna 2001), 2nd (Prague 2004), and 3rd (Zurich 2008) International Consensus Conferences on Concussion in Sport. This consensus paper includes a summary of concussion and its management.

5. Giza CC, Kutcher JS, Ashwal S, Barth J, Getchius TS, Gioia GA, et al. Summary of evidence-based guideline update: evaluation and management of concussion in sports: report of the Guideline Development Subcommittee of the American Academy of Neurology. Neurology. 2013;80(24):22507.

6. Harmon KG, Drezner JA, Gammons M, Guskiewicz K, Halstead M, Herring SA, et al. American Medical Society for Sports Medicine position statement: concussion in sport. Br J Sports Med. 2013;47(1):15-26.
7. Sports-Related Concussions in Youth: Improving the Science, Changing the Culture. Committee on SportsRelated Concussions in Youth; Board on Children, Youth and Families; Institute of Medicine; National Research Council; Graham R, Rivara FP, Ford MA, Spicer CM. Eds. Washington (DC): National Academies Press (US); 2014 Feb. http://www.iom.edu/ Reports/2013/Sports-Related-Concussions-in-YouthImproving-the-Science-Changing-the-Culture-aspx. Accessed 23 November, 2014.

8. Emery CA, Kang J, Shrier I, Goulet C, Hagel BE, Benson BW, et al. Risk of injury associated with body checking among youth ice hockey players. JAMA. 2010;303(22):2265-72.

9. $\quad$ Daniel RW, Rowson S, Duma SM. Head impact exposure in youth football. Ann Biomed Eng. 2012;40(4):976-81.

This study demonstrates that youth football players age 7-8 years old can produce high magnitude $(>80 \mathrm{G}$ ) linear acceleration forces in the range of concussion-causing impacts measured in adults. Additionally, the majority of these high magnitude impacts occurred during practice, which brings to attention the need to restructure youth football practices to reduce head impact exposures in this setting.

10. Emery C, Kang J, Shrier I, Goulet C, Hagel B, Benson B, et al. Risk of injury associated with bodychecking experience among youth hockey players. CMAJ. 2011;183(11):1249-56.

11. Nocera J. Should kids play football? http://www. nytimes.com/2012/12/15/opinion/should-kids-playfootball.html. Accessed 23 November, 2014.

12. USA Football. http://usafootball.com/headsup/. Accessed 23 November, 2014.

13. USA Hockey. Checking the Right Way for Youth Hockey. A Publication of the USA Hockey Coaching Education Program. http://assets.ngin.com/ 
attachments/document/0042/2205/Checking_ Manual_FINAL.pdf. Accessed 23 November, 2014.

14. Smith AM, Stuart MJ, Gaz DV, Twardoski CP, Stuart MB, Margeneau D, et al. Behavioral modification to reduce concussion in collision sports: ice hockey. Curr Sports Med Rep. 2013;12(6):356-9.

This article provides important commentary regarding the increased awareness of sport-related concussion, the limitations of modern protective equipment in preventing concussion, and the promise of behavioral modification programs such as Fair Play to reduce head and neck neurotrauma.

15. Kroshus E, Daneshvar DH, Baugh CM, Nowinski CJ, Cantu RC. NCAA concussion education in ice hockey: an ineffective mandate. Br J Sports Med. 2014;48(2):135-40.

16. Collins CL, Fletcher EN, Fields SK, Kluchurosky L, Rohrkemper MK, Comstock RD, et al. Neck strength: a protective factor reducing risk for concussion in high school sports. J Prim Prev. 2014;35(5):309-19.

This study identifies important predictors for sport-related concussion among male and female high school athletes, including smaller mean neck circumference, smaller mean neck to head circumference ration, and weaker mean overall neck strength. Identification of at-risk athletes using a pre-season screening process could be useful in targeting these athletes for concussion prevention programs.

17. Eckner JT, Oh YK, Joshi MS, Richardson JK, AstonMiller JA. Effect of neck muscle strength and anticipatory cervical muscle activation on the kinematic response of the head to impulsive loads. Am J Sports Med. 2014;42(3):566-76.

This study demonstrates that neck strength and anticipation of impact are 2 risk factors for concussion that can potentially be modified in contact sport athletes.

18. Roberts WO, Brust JD, Leonard B, Hebert BJ. Fair-play rules and injury reduction in ice hockey. Arch Pediatr Adolesc Med. 1996;150(2):140-5.

19. Klein JZ. Fair Play shows up in the standings. http:// query.nytimes.com/gst/fullpage.html?res=
9C03E5D6133EF931A15751C1A9669D8B63.

Accessed 23 November, 2014.

20. Vermont State Amateur Hockey Association. Annual guide: 2014-2015. http://assets.ngin.com/ attachments/document/0062/1632/

VTHockeyAnnualGuide.pdf. Accessed 20 December, 2014.

21. Belson K. A 5-concussion Pee Wee game leads to penalties for the adults. http://www.nytimes.com/2012/ 10/23/sports/football/pee-wee-football-game-withconcussions-brings-penalties-for-adults.html? pagewanted=all\&_r=0. Accessed 30 November, 2014.

22. Butterfield F. Man convicted in fatal beating in dispute at son's hockey game. http://www.nytimes.com/2002/ 01/12/us/man-convicted-in-fatal-beating-in-disputeat-son-s-hockey-game.html. Accessed 30 November, 2014.

23. Toporek B. Eighth grade football players racking up college-scholarship offers. http://blogs.edweek.org/ edweek/schooled_in_sports/2013/06/eighth_grade_ football_players_racking_up_college_scholarship_ offers.html. Accessed 30 November, 2014.

24. Johns Hopkins gets two more commitments from freshmen. http://articles.baltimoresun.com/2013-1227/sports/bal-recruiting-notes-johns-hopkins-lacrossegets-two-more-commitments-from-freshmen20131227_1_philly-showcase-terrapin-classicmaverik-showtime. Accessed 30 November, 2014.

25. Graham G. For boys lacrosse players, the recruiting process is starting earlier than ever. http://articles. baltimoresun.com/2012-03-16/sports/bs-va-spspring-sports-preview-feature-2012-20120317_1_ boys-lacrosse-rick-brocato-hopkins-coach-davepietramala. Accessed 30 November, 2014.

26. Klein JZ. Plan would ban fighting in top U.S. amateur hockey leagues. http://www.nytimes.com/2013/12/ 19/sports/hockey/plan-would-ban-fighting-in-top-usamateur-hockey-leagues.html. Accessed 30 November, 2014. 